\section{Manual para la Estandarización de Estudios Clínicos en Chile: desde la concepción hasta la publicación}

\section{Handbook for the Standardization of Clinical Studies in Chile: from conception to publication}

Impreso por la Universidad de los Andes, Santiago, octubre de 2017. 140 páginas.

Disponible con acceso libre en www.ispch.cl/anamed

Este Manual, de reciente presentación, es una obra generada por docentes de la Universidad de los Andes, como fruto de un proyecto que contó con el apoyo de esa Universidad, del Instituto de Salud Pública de Chile (institución mandante), del Hospital de Niños Dr. Luis Calvo Mackenna (institución beneficiaria) y de la Corporación de Fomento de la Producción (CORFO), institución financiadora que lo calificó "Proyecto de Bien Público". Sus autoras son las Dras. María Teresa Valenzuela (investigadora principal), Cinthya Urquidi (co-investigadora) y Celmira Martínez (coordinadora), apoyadas por quince colaboradores de distintas profesiones de la salud, de universidades chilenas y norteamericanas, el Ministerio de Salud, el Instituto de Salud Pública de Chile, la Unidad de Investigación del Hospital Calvo Mackenna, y otros organismos.

$\mathrm{Al}$ decir de sus autoras, "el Manual pretende ser una guía de ruta, que contiene los pasos esenciales a seguir a partir del momento en que se plantea la necesidad de evaluar la eficacia terapéutica de un nutracéutico o de un fármaco en desarrollo". Este propósito se cumple cabalmente mediante una acuciosa recopilación de guías internacionales sobre estudios clínicos, en general, y ensayos clínicos, en particular, la legislación internacional y la de nuestro país.

Con este propósito claramente definido, el Manual prestará ayuda no solo a quienes planteen interés por realizar un ensayo clínico sino también a quienes están ya participando en uno de ellos, porque permitirá saber cómo partir y cómo continuar, paso a paso, respetando disposiciones lógicas, técnicas y legales, guiándolos para realizar su trabajo con estricto rigor científico y ético.

El Manual se inicia dando una perspectiva histórica a los ensayos clínicos, seguida por una descripción de elementos útiles para recorrer su texto, tales como un glosario, una lista de abre- viaturas que es indispensable manejar (con sus alternativas en idiomas español e inglés), y una descripción de las cuatro fases que deben cumplir los estudios clínicos. Antes de entrar a describir los ensayos clínicos, que son los estudios de fase III, se dejan absolutamente claras las disposiciones éticas respectivas, el rol de los Comités de Ética de la Investigación Clínica y del Instituto de Salud Pública, y las normativas internacionales $y$ nacionales que deben respetarse en iniciativas que ponen en riesgo a seres humanos. Puede que el lector conozca ya algunos o muchos de estos elementos, pero este Manual los revive de forma clara y breve, con una armonía en la redacción que es difícil de conseguir en documentos con multi autoría. El corpus del Manual se enfoca en las etapas sucesivas que debe cumplir un ensayo clínico: la concepción del estudio, su preparación, ejecución, el análisis de los datos, el cierre del estudio y su publicación. Cada paso se explica con precisión, con un lenguaje fluido que respeta lo científico, pero prescinde de una terminología rebuscada que podría confundir o cansar al lector. El texto se acompaña de Figuras y Tablas bien diseñadas, que cumplen a cabalidad la misión de ayudar a comprender el mensaje escrito; algunas Figuras son flujogramas que guían la ruta de los investigadores, siendo particularmente útiles al señalar en qué momento o etapa se produjo un bloqueo que obliga a devolverse en el flujo de acciones para corregir la falla. En oportunidades apropiadas, se dirige la atención a documentos y sitios web de organismos expertos en investigación biomédica y clínica, donde encontrará una información complementaria actualizada y con validez internacional. Este Manual será una herramienta que contribuirá a fomentar altos estándares en la investigación clínica en nuestro país.

Al presentar este comentario bibliográfico declaro tener un evidente conflicto de intereses con el libro, por cuanto sus autoras me solicitaron que participara en calidad de "revisor" una vez que lo hubieron terminado. Fue una tarea grata y me complace señalar a los lectores que durante una prolongada carrera profesional como investigador básico y clínico, y editor de la Revista Médica de Chile, no he encontrado una obra sobre esta materia, en idioma español, que sea tan simple, sólida y clara.

Dr. Humberto Reyes B. Editor Emérito, Revista Médica de Chile. 